\title{
A DOCUMENTAÇÃO PEDAGÓGICA EM UMA EXPERIÊNCIA FORMATIVA NA EDUCAÇÃO INFANTIL: marcas de um percurso de encontro com o outro
}

\author{
Onileda de Souza Matta Guimarães \\ Professora da Rede Pública de Santa Catarina - SC \\ Luciane Pandini Simiano \\ Universidade do Sul de Santa Catarina - UNISUL \\ Simone Bicca Charczuk \\ Universidade Federal do Rio Grande do Sul - UFRGS
}

\begin{abstract}
Resumo
O presente texto tem por foco analisar como o percurso de documentar contribui para o acolhimento da alteridade em Educação Infantil. A pesquisa, desenvolvida em uma perspectiva qualitativa, foi realizada no âmbito do Mestrado em Educação em uma universidade do sul do estado de Santa Catarina. Teve como sujeitos um grupo de dez professoras que atuam na Educação Infantil na mesma região e que participaram de uma experiência formativa realizada a partir de um curso de extensão tecido pelo percurso de documentar. A observação participante, registros escritos, fotográficos, audiovisuais e, sobretudo, o estar junto com as professoras foram os instrumentos de pesquisa. A partir do diálogo entre diferentes autores como Levinas, Bárcena e Mèlich, Hermann, Rinaldi, Simiano, Mariotto, destaca-se o princípio ético da alteridade no gesto de documentar, porque ele pauta relações estabelecidas entre crianças e adultos no cotidiano educativo. A experiência formativa com professores construída no percurso de documentar permite questionar pressupostos naturalizados na prática pedagógica, ampliando possibilidades de pensar sobre condições de acolhimento e reconhecimento do outro na Educação Infantil.
\end{abstract}

Palavras-chave: Educação Infantil. Documentação Pedagógica. Alteridade.

\begin{abstract}
The present study aims at analyzing how the documentation path contributes to the acceptance of otherness in Children Education. The research has been developed upon a qualitative perspective as part of a master's degree curriculum in the education field at a university facility in the south of Santa Catarina, Brazil. A group of ten teachers who work within the same territorial area and who have similar training experience in the documentation path was the main subject for the present study. Participatory observation, written records, pictures, audiovisual reports and the time spent among the group of teachers were the main research tools applied, the last one being the most meaningful one. Based on different authors' perspectives, such as Levinas, Bárcena \& Mèlich, Hermann, Rinaldi, Simiano, Mariotto, documenting the ethical principle of otherness stands out and that is due to the fact that it founds the relationship among children and adults in their day-by-day educational life. Teachers' formative experience that has been built within the documentation path allows questioning certain naturalized pedagogical assumptions already so naturalized in the pedagogical practice, as well as broadening thinking possibilites about ways of welcoming and recognizing other in Children Education.
\end{abstract}

Keywords: Children Education. Pedagogical documentation. Otherness.

ISSN 1645-1384 (online) www.curriculosemfronteiras.org

http://dx.doi.org/10.35786/1645-1384.v21.n1.9 
"Uns nasceram para cantar, outros para dançar, outros nasceram simplesmente para serem outros." (Mia Couto)

A legislação da Educação Infantil, desde a promulgação da Constituição Federal (1988) até a publicação das Diretrizes Curriculares Nacionais da Educação Infantil (DCNEIs) (BRASIL, 2009), trouxe importantes deliberações e representa uma mudança significativa nos modos de compreender a função social e política desse nível de ensino. Como destaca Mariotto (2009, p. 16), "[...] com a nova [Lei de Diretrizes e Bases da Educação Nacional] LDB (1996), a creche passou a ter um estatuto educacional e não mais apenas assistencial”, o que enfatiza o espaço da creche e da Educação Infantil como um lugar privilegiado de filiação das crianças pequenas no universo da cultura.

As DCNEIs inscrevem na letra da lei o desejo de que possamos produzir uma educação sustentada pelos princípios éticos, políticos e estéticos. Construir uma proposta educativa pautada por esses princípios requer um encontro edificado sobre a receptividade e acolhida ao outro. Uma configuração político-pedagógica que implica questionamentos diferenciados: como acolher aquele que chega na Educação Infantil? Qual o papel do outro na educação e cuidado de crianças pequenas? Como sustentar relações educativas pautadas em tais princípios?

No Brasil, são recentes os estudos que investigam tais questões. Podemos citar, nesse sentido, os trabalhos de Rossetti-Ferreira (1988), Coutinho (2002), Schmitt (2009) e Simiano (2015), ao afirmarem que as crianças bem pequenas são ativas e competentes nas relações e apontam a socialização, as interações e as aprendizagens entre adultos e crianças como pilares que sustentam uma "pedagogia da educação infantil". Estes processos acontecem em todas as atividades cotidianas, mas, por serem sutis, ainda permanecem invisíveis, despercebidos. Nesse contexto, segundo Simiano (2015), é preciso criar visibilidades, reconhecer, valorizar preciosidades, as quais, se não forem narradas, correm o risco de se perderem. Pequenos encantamentos registrados, inventados, documentados, narrados no cotidiano...

O presente texto aborda tais questões, ao analisar o percurso de documentar e as possibilidades de acolhimento e reconhecimento do outro na Educação Infantil. As indagações e reflexões estão pautadas em elementos de uma pesquisa de Mestrado em Educação, realizada em 2019, que contemplou uma instituição de Educação Infantil situada na região sul do estado de Santa Catarina (GUIMARÃES, 2019). O enfoque privilegiado de análise é uma experiência formativa realizada a partir de um curso de extensão, com duração de oito meses, ofertado a um grupo de dez professoras que atuam na Educação Infantil. O ponto de partida foi a seguinte questão: pode o percurso de documentar ser capaz de criar condições de acolhimento e reconhecimento do outro na Educação Infantil? Trata-se de uma pesquisa qualitativa (ANDRÉ, 2003). Os instrumentos foram a formação, observação participante, registros gráficos e audiovisuais e análise das documentações pedagógicas produzidas pelos professores.

Escolher um percurso de pesquisa por meio de uma experiência formativa que tem como via a documentação pedagógica é um caminho que não é reto, nem direto, pois “[...] a 
experiência não é o caminho até um objetivo previsto, até uma meta que se conhece de antemão, mas é uma abertura para o desconhecido, para o que não se pode antecipar nem pré-ver nem pré-dizer" (LARROSA, 2002, p. 28). Nesse sentido, compreendemos com Walter Benjamin (1989) que método é desvio, outra racionalidade do fazer investigativo. Simiano (2018) explica que entender o método como desvio envolve um pensamento minucioso e hesitante que sempre volta ao seu objeto por diversos caminhos. A autora aproxima tal perspectiva do que Benjamin chama de contemplação, ou seja, uma espécie de atenção ao mesmo tempo leve e intensa, a qual indica um sujeito que saiba deter-se admirado, respeitoso, hesitante e talvez perdido, em que as coisas para se ver se dão lentamente. Essa perspectiva permite tecer os fios da pesquisa com/no vivido.

A análise dos registros colhidos durante a realização do curso de extensão implicou diferentes exercícios de seleção e categorização das anotações, cenas, fotos e documentações. Como eixo de análise destacam-se, neste texto, o percurso de documentar e as possibilidades de acolhimento e reconhecimento do outro na Educação Infantil.

\section{Notas sobre alteridade e documentação pedagógica}

As complexas condições de possibilidade da educação impressas pelo tempo cultural e histórico em que vivemos nos fazem pensar o quanto a educação é propícia ao desenvolvimento de uma ética da alteridade, pois tem por princípio o diálogo e o respeito ao outro como compromisso de abertura a uma comunidade de racionalidades plurais.

Hermann (2014) propõe uma reflexão sobre alteridade e educação que faz do outro um tema da educação e da instituição educativa um lugar potente de encontro, tendo a possibilidade de promover a ética da alteridade num espaço de diálogo e escuta sensível. Nesse sentido, Johann (2009), a partir do diálogo com Hermann (2014), ressalta que "ética é uma permanente reflexão a respeito dos valores que orientarão a travessia humana" (p. 43). É na constante reflexão desse princípio que o ser humano poderá construir uma sociedade mais justa, a partir de ações de acolhida, alteridade e hospitalidade, com base em um compromisso ético que vai além do $E u$, ao encontro do Outro.

Deste modo, o princípio ético é uma forma de acolhida ao outro que não sou eu, mas com quem devo me relacionar de forma dialógica, problematizando os valores da vida coletiva para o bem comum. Uma educação com fins éticos, portanto, constrói conhecimento e está atenta e preocupada com a humanização.

Considerar a educação como um acontecimento ético é compreender que a ação educativa só tem sentido quando resulta de uma prática consciente que leva ao encontro do outro. Entrar em relação com o outro nem sempre é tarefa fácil, exige um exercício constante de alteridade, de se colocar no seu lugar, de encontrar meios onde o respeito e a responsabilidade para com aquele sejam a premissa desta relação.

[...] O outro que nos atrai, nos atrai, nos perturba e nos convoca a acolhê-lo. Tornamo-nos quem somos pela resposta a essa convocação e também somos, 
muitas vezes, surpreendidos pelo outro que nos habita. Assim, a própria ética se constitui nas complexas respostas produzidas pela interação do outro (HERMANN, 2014, p. 13).

O deslocamento que se faz na direção do Outro remete ao princípio ético que reconhece a alteridade e, ao reconhecê-la, acolhe este outro com responsabilidade. Esta relação ética é construída no encontro com o outro, tendo o respeito como premissa, de forma acolhedora e hospitaleira. Não é uma relação de colonização, mas de acolhimento. Valorizar este princípio é reconhecer o outro como alguém que traz uma novidade, um novo modo de agir que rompe com estruturas pré-definidas, construindo outros significados.

Bárcena e Mèlich (2000, p. 83) propõem pensar a educação como um acontecimento ético. Nas palavras dos autores, “a ética possibilita que a ação seja nascimento. [...] Não há ética sem novidade, sem ruptura, sem inovação e sem repetição. A monotonia rouba o sentido do que fazemos... É a angústia da existência”. É preciso valorizar cada relação que se inicia como uma nova possibilidade de agir. A riqueza que está na diferença, visto que cada um traz uma experiência de vida, valores, crenças, concepções, fazem parte da sua subjetividade e, ao serem reconhecidos, complementam e permitem a construção de um novo sentido e significado. Partindo desta premissa, faz-se necessário construir uma prática de educação acolhedora.

Para Arendt (2007, p. 17), as crianças pequenas trazem uma novidade ao mundo, pois "o novo começo a cada nascimento pode fazer-se sentir no mundo somente porque o recémchegado possui a capacidade de iniciar algo novo, isto é, de agir". A chegada de uma criança ao mundo transforma a realidade de todos à sua volta. Ao chegar, ela interrompe e entra em continuidade conosco, completando e agregando outros sentidos e significados. Desta forma, cabe indagarmos: qual o papel da educação em relação àqueles que nascem? O que significa para a professora recebê-los? Como a educação vem respondendo a essa chegada?

A Educação Infantil é o primeiro espaço de educação coletiva. Contexto onde as crianças fazem as primeiras experiências de convivência na diversidade. Um lugar tecido no encontro entre adultos e crianças que se relacionam e compartilham sentidos e significados. Pensar em como estar à disposição daquele que vem, respeitando sua alteridade, requer estar aberto à novidade, presente a cada novo nascimento. Nesse contexto, a presença do adulto que acolhe torna-se crucial, pois, conforme pontua Mariotto (2009), a constituição subjetiva do pequeno ser não depende somente da maturação orgânica e da aquisição de funções, mas prioritariamente da inserção que o adulto faz da criança no universo simbólico a partir do encontro com a linguagem. Ressalta ainda a autora, afirmando que "o que marca o compasso do desenvolvimento é o desejo do Outro [aqui entendido como cuidador primário que apresenta as primeiras inscrições do bebê na cultura] e não os ponteiros de um relógio" (MARIOTTO, 2009, p. 50).

Pensar a educação a partir da ética é estar aberto para acolher a novidade que há no outro. A diversidade no contexto educacional requer de nós uma postura ética, que acolhe cada um que faz parte desse contexto, sejam as crianças, as famílias, os professores e a comunidade em que estão inseridas. Esses encontros nos interpelam a olhar o outro com estranhamento e 
nos convocam a um novo relacionamento. Ir ao encontro do estranho requer uma abertura para o inesperado, para o desconhecido.

Consideramos que a proposta de leitura freudiana do conceito de estranho (ou inquietante) também nos auxilia a pensar em uma perspectiva ética em educação que leve em consideração a inclusão do respeito ao outro, ao diferente, pois este outro também habita em nós. Nesse sentido, Freud (1919/2010) afirma que "o inquietante é aquela espécie de coisa assustadora que remonta ao que é há muito conhecido, ao bastante familiar" (p. 331).

Ainda a esse respeito, Rinaldi (2017) parte da ideia de que escutar as crianças e suas elaborações nos leva ao encontro deste princípio ético da alteridade. Para tanto, a autora propõe a pedagogia da escuta. Esta escuta se faz a partir de um deslocamento na direção do outro. No seu entender, seria uma ética hospitaleira, uma abertura para encontrar o Outro.

Uma ética de um encontro edificado sobre a receptividade e a hospitalidade ao Outro - uma abertura para a diferença do Outro, para a vinda do Outro. Ela envolve uma relação ética de abertura ao Outro, tentando escutar o Outro em sua própria posição e experiência, sem tratar o Outro como igual (RINALDI, 2017, p. 43).

Educar na diversidade é valorizar a relação na pluralidade, acolhendo o outro no seu modo de ver, sentir e pensar. "Pensar a infância como o Outro, que nos olha, interpela-nos, supõe suspender certezas e admitir um possível 'não saber', o qual se renova frente a ela" (SIMIANO, 2015, p. 71, grifo da autora). Olhar e acolher o outro com olhar diferente é estar disposto a construir e desconstruir conceitos. Estar atento à interrogação do Outro, oferecendo uma escuta sensível às suas necessidades.

As DCNEIs (BRASIL, 2010) estabelecem que as práticas educativas para a primeira infância precisam ser sustentadas pelos princípios éticos, políticos e estéticos. Tendo como ponto de partida o princípio ético "da autonomia, da responsabilidade, da solidariedade e do respeito ao bem comum, ao meio ambiente e às diferentes culturas, identidades e singularidades" (BRASIL, 2010), pretendemos tecer algumas reflexões sobre esse princípio e o processo de documentação pedagógica no contexto da Educação Infantil.

No Brasil é consensual, entre teóricos e pesquisadores da área, a importância da observação, registro e documentação pedagógica no contexto da Educação Infantil. Contudo, embora as teorias e diretrizes legais apontem para a importância de tais princípios no contexto educativo, essas indicações não são suficientes, há dificuldades para sustentar tal processo em função de práticas pedagógicas frágeis que comumente associam a documentação à atividade burocrática, não a compreendendo como um processo que possibilita sustentar relações educativas com crianças pequenas.

Em busca de construir um olhar mais legitimador para tais questões, estabelecemos um diálogo com os estudos da abordagem italiana para a Educação Infantil. As contribuições da pedagogia italiana foram difundidas no Brasil a partir da década de 90 , tendo a documentação pedagógica como eixo central dessa proposta. Malaguzzi (1999) foi o precursor de tal 
proposta, para ele a documentação pedagógica é sustentada a partir dos princípios do olhar, da escuta, do registro, da interpretação e construção de uma narrativa.

Para a pedagogia italiana o gesto de olhar e escutar estão intimamente associados. Uma escuta sensível requer sensibilidade, olhar sem juízos prévios, sem pressa, observando como se estivesse vendo pela primeira vez. "Escuta, portanto, como metáfora para a abertura e a sensibilidade de ouvir e ser ouvido" (RINALDI, 2017, p. 124). Esta escuta sensível é que nos leva ao encontro do princípio ético, uma ética pautada nas relações de acolhimento e reconhecimento da alteridade.

Segundo Simiano (2015, p. 59), "no processo de documentação pedagógica, torna-se primordial ver, ouvir, sentir e perceber os bebês e crianças pequenas. Porém, estes atos não são naturais. Precisam ser aprendidos". Se esse exercício precisa ser aprendido, como é possível tal aprendizagem?

Exercitar um olhar sensível é colocar-se disponível, com uma postura hospitaleira, escutando com todos os sentidos o que as crianças sinalizam. Mas não basta só ouvir, é necessário registrar e encontrar formas de narrar. Os registros tornam-se fonte de pesquisa para o professor, permitindo trazer à memória fatos e experiências vividos.

Registrar é uma forma de capturar o vivido para que este não caia no esquecimento. Muitas são as formas de registros, como diário de bordo, máquinas fotográficas, ou recursos audiovisuais que auxiliam o professor neste processo de documentar. Não existe um instrumento melhor ou pior, vai depender da intencionalidade que se tem na hora de documentar. Para isto é fundamental saber por que, para que, para quem e como. Dependendo do que se quer contar, escolhe-se também qual instrumento usar. Documentar implica uma escolha, que passa pela interpretação.

$\mathrm{O}$ ato de interpretar acontece de forma coletiva, por meio do qual professores têm a oportunidade de compartilhar suas observações, seus registros, falar das suas certezas e desafios, proporcionando um momento de trocas e reflexões. Olhar para estes registros como fonte de conhecimento e crescimento profissional permite criar outros significados. "Os documentos discutidos e examinados tornam-se ferramentas de comunicação quando nós, como professores, trabalhamos juntos para selecioná-los, organizá-los e identificá-los a fim de dar significado" (GANDINI; GOLDHABER, 2002, p. 155).

Quando estas observações e registros são compartilhados com o outro, outras interpretações e sentidos podem vir à tona, gerando outros significados que contribuem para a formação de todos os envolvidos nesse processo. "Uma espécie de interpretação em companhia, uma vez que novas apropriações podem ser feitas no encontro com outras professoras" (SIMIANO, 2015, p. 61). Essa interpretação em companhia permite encontrar o outro e, juntos, refletir sobre o processo vivido.

Após serem refletidos e interpretados, chega o momento de escolher a forma que se quer narrar. As narrativas podem ser apresentadas por meio de painéis, panfletos, portfólios, diários, cartas, slides, trabalhos bi e tridimensionais: cada professor documenta de acordo com a intencionalidade do que quer contar e com quem deseja compartilhar. Não existe uma forma, assim como as crianças têm cem linguagens, o professor pode escolher cem formas de narrar. 
Ao compreender a documentação pedagógica como um processo narrativo, tecido com os fios da experiência, no encontro entre adultos e crianças, considera-se a necessidade de pensar os espaços coletivos de Educação Infantil como lugar de experiência onde, por meio das relações que emergem no cotidiano, as narrativas necessitam ser tecidas e alicerçadas em um princípio ético de acolhimento e respeito às singularidades. Nesse sentido, cabe indagar: como os espaços de Educação Infantil podem se configurar como lugar de experiência?

Pensar o espaço de Educação Infantil como um lugar potente de experiência significa romper com a linearidade, permitir-se tocar e ser tocado pelo inusitado, pelo imprevisível. É preciso olhar para as crianças sem pressa, suspender as certezas e valorizar as relações do cotidiano. Concordamos com Larrosa (2016, p. 25), quando explicita que:

A experiência, a possibilidade de que algo nos aconteça ou nos toque, requer um gesto de interrupção, um gesto que é quase impossível nos tempos que correm: requer parar para pensar, parar para olhar, parar para escutar, pensar mais devagar, olhar mais devagar, e escutar mais devagar; parar para sentir, sentir mais devagar, demorar-se nos detalhes, suspender a opinião, suspender o juízo, suspender a vontade, suspender o automatismo da ação, cultivar a atenção e a delicadeza, abrir os olhos e os ouvidos, falar sobre o que nos acontece, aprender a lentidão, escutar os outros, cultivar a arte do encontro, calar muito, ter paciência e dar-se tempo e espaço.

Para que a experiência aconteça é preciso ir mais devagar, valorizar o cotidiano, estar disponível para entrar em relação com a criança e, juntos, construir uma nova história. Nós, seres humanos, constituímo-nos por meio de histórias, que são entrelaçadas no dia a dia ao nos colocarmos em relação com o outro.

Conforme Walter Benjamin, a narrativa é uma forma de intercambiar experiências. Segundo o autor, o mundo moderno foi empobrecido com a falta de experiência. Muitas coisas nos passam todos os dias, mas poucas nos marcam. "Cada manhã recebemos notícias de todo o mundo. E, no entanto somos pobres em histórias surpreendentes" (BENJAMIN, 1994, p. 203).

Olhar para os espaços de Educação Infantil como lugar de experiência é acreditar que, na potência das relações que emergem do cotidiano, muitas narrativas podem ser tecidas. Simiano (2015, p. 13), em diálogo com Walter Benjamin, estabelece uma relação entre o professor e o narrador, e a "documentação pedagógica como uma narrativa peculiar que é constituída na materialidade das 'coisas' pelas quais a criança bem pequena se faz falar e é falada".

Esses momentos que emergem do cotidiano, no encontro de adultos e crianças, são contextos ricos de experiência, pois por meio das narrativas é que vamos nos constituindo como sujeitos, formando nosso modo de pensar e de agir, em um mundo em que nos é narrado e que, ao mesmo tempo, narramos. Ao observar, registrar e narrar as experiências das crianças no cotidiano, o professor oferece outros sentidos para aqueles que ali convivem. Bárcena e Mèlich (2000) defendem a ideia de que a ação humana e, em especial, a ação educativa, torna-se possível de ser narrada, de criar uma história digna de ser contada. 
Neste sentido, o professor, ao registrar, narrar e materializar as experiências educativas das crianças constitui-se como autor, não apenas um repetidor, um tarefeiro. A documentação pedagógica configura-se como narrativa peculiar, tecida com os fios da experiência no encontro cotidiano de crianças e adultos. É um documento que dá legitimidade às experiências das crianças em um determinado tempo e espaço, materializando, criando memórias e gerando outros significados. Em um tempo de constituição da criança como sujeito, ao narrar as experiências construídas no encontro, o professor empresta as palavras para a criança fazer-se dizer e também faz-se dizer no encontro com cada criança.

E assim a criança se constitui como sujeito, por meio das relações e narrativas que são tecidas no encontro com o outro. Concordamos com Bárcena e Mèlich (2000, p. 93, grifos dos autores), quando afirmam que "construímos nossa identidade narrativamente, o que é o mesmo, através das leituras históricas e de ficção, por meio das quais vamos, cada vez mais, compondo nosso personagem".

Essa é a principal função da documentação, levar crianças e adultos a encontrarem significados para o que fazem, descobrem, experimentam. Não se trata de oferecer um sentido único, mas o possível (SIMIANO, 2015). Para isto, a construção de textos abertos é fundamental, reconhecendo a alteridade da infância.

\section{O processo de documentação pedagógica na Educação Infantil: sobre o acolhimento da alteridade em Educação Infantil}

No processo de construção das documentações pedagógicas a partir da experiência formativa com professoras da Educação Infantil, assumimos um compromisso ético durante todos os encontros, que revelaram a acolhida e a hospitalidade ao Outro. As professoras foram ouvidas e, assim, compartilharam as experiências significativas que haviam lhes tocado no encontro com as crianças. O relato da professora Júlia ${ }^{1}$ revela uma experiência que a provoca e convoca a refletir e documentar: "Alice ( 4 anos e 2 meses) me chama e fala: 'Tia, o fulano e o outro riscou a parede'. Aí, no primeiro momento, eu olhei e disse: 'Meu Deus! Vocês riscaram a parede!'. Tá... daí fui lá, peguei o pano, limpei a parede, tudo e fui embora" [sic]. (Áudio transcrito, relato professora Júlia - 20/09/2018).

Ao relatar sua experiência, a professora Júlia fala que, no primeiro momento, ao ver as paredes riscadas, sua iniciativa foi limpar a parede, olhando para aquelas marcas significando sujeira. Mas, em um segundo momento, ela relatou que, a partir dos encontros no percurso de experiência formativa que estávamos realizando, passou a prestar mais atenção nas crianças, a ressignificar com elas o sentido de suas ações.

Um olhar sensível. Uma escuta que reconhece o outro. Leva a professora Júlia à reflexão:

Daí, quando cheguei em casa, fiquei pensando: 'Meu Deus, eles escrevem tanto... a parede da casinha tá toda riscada... eles escrevem tanto na parede, por que será? O que eles queriam dizer? Eles tinham a necessidade de escrever na parede, né?! 
Daí, eu fiquei pensando no que eu ia fazer. Então hoje eu cheguei e mudei a sala toda e deixei várias paredes e botei papel. Não falei nada pra eles. Só botei papel e um monte de canetinha, a mesma que eles escreveram na parede. Isso foi hoje. E não falei nada. Daí eles ficaram me olhando, se olharam, mas eu não falei nada. Aí um perguntou pro outro. E eu não falei nada, fiquei lá quietinha. 'Será que pode escrever?' [sic] (Áudio transcrito, relato professora Júlia - 20/09/2018).

Admitir um possível não saber diante do acontecido permite reconhecer outros modos de ser e estar no mundo. O estranhamento daquilo que antes parecia tão familiar agora intriga e desperta na professora Júlia uma abertura ao outro. Um novo encontro com o outro, um novo encontro consigo como outra.

Ao refletir e compartilhar os seus registros, a professora percebe que as crianças são ativas, protagonistas, potentes e autoras, fazendo outra leitura das suas marcas. Ao olhar, escutar as crianças, a professora Júlia não mais compreende os riscos na parede como sujeira ou ato transgressor, mas passa a compreender o desejo de as crianças se expressarem e deixarem suas marcas no espaço educativo por elas habitado. As marcas deixadas pelo caminho constituem a identidade e contam a história desse grupo de meninos e meninas. "Sentir-se parte, marcar, deixar rastros é constitutivo do sujeito. Acolher a alteridade, registrar a singularidade na creche possibilita um sentido de pertença" (SIMIANO, 2015, p. $105)$.

No processo de documentar, a professora desloca seu olhar e passa a reconhecer e legitimar as ações de expressão gráfica das crianças, constrói outros sentidos e significados. Reconhecendo essa experiência, a professora elegeu, construiu uma documentação pedagógica em forma de livreto para materializar essa narrativa. Assim nasceu a documentação: Nossas Marcas..., como mostra a figura 1.

Figura 1 - Nossas marcas...

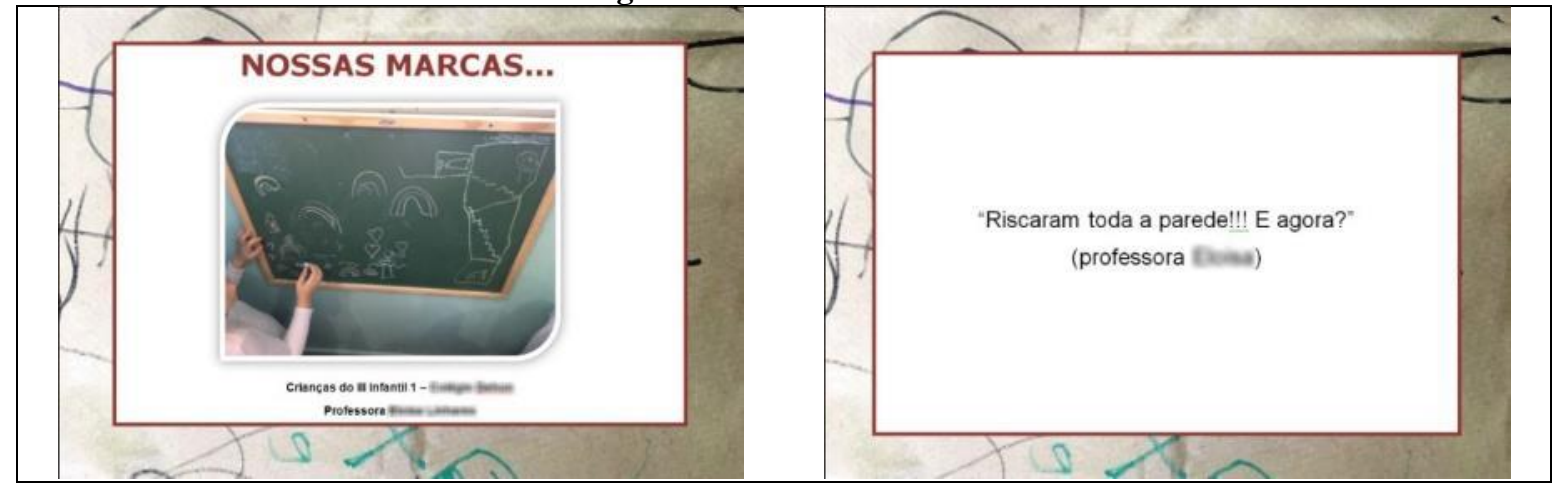




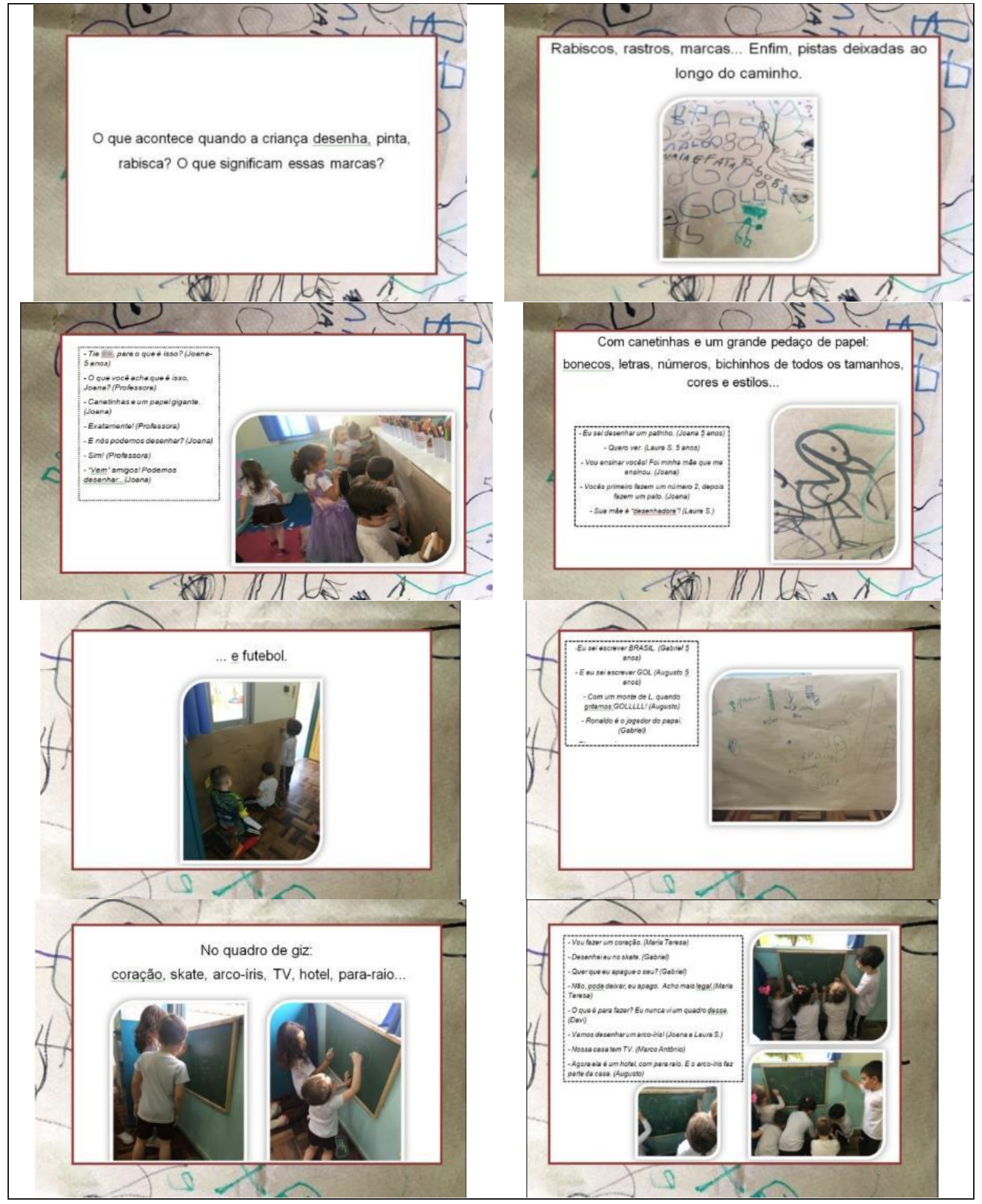




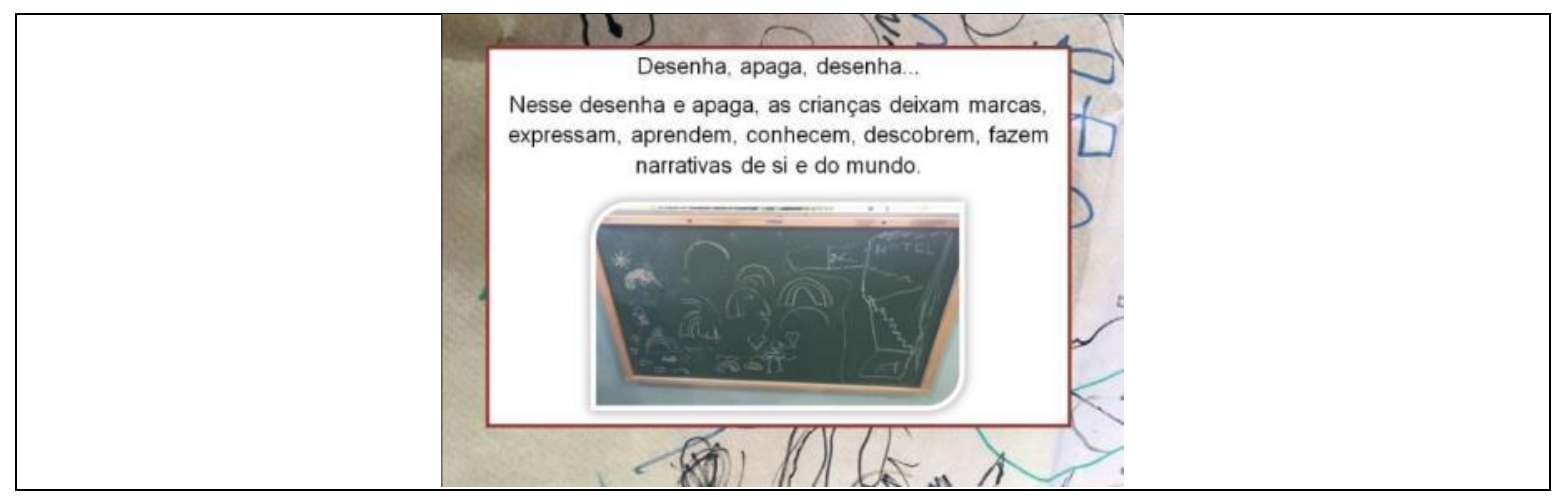

Fonte: Acervo da pesquisadora (2018).

Rastros, pistas deixadas ao longo do caminho... As crianças deixam marcas, expressamse, conhecem, aprendem e narram a experiência de si e do mundo. Os rabiscos que eram vistos como sujeira passam a ser interpretados como bordas que sustentam a construção de uma narrativa. A professora Júlia, ao narrar e materializar os rabiscos das crianças em forma de um livro, elaborou outro sentido e significado. "A narrativa é um convite ao pensamento, à construção de significados, à elaboração de sentido" (BÁRCENA; MÈLICH, 2000, p. 122).

O compartilhamento da documentação Nossas Marcas vai ao encontro da ética do acolhimento. Acolher as especificidades das crianças e assumir outra postura diante desses Outros que nos interpelam, e documentar levam, de acordo com Rinaldi (2017, p. 237), "a entender e a mudar a sua identidade como educador, pode ser um convite à reflexão dos seus valores".

A professora Júlia, ao refletir sobre o interesse das crianças em escrever, dispôs, na sua sala, um espaço para que as crianças possam escrever e deixar as suas marcas, reconhecendo a criança como um sujeito de direitos que deseja sentir-se pertencente ao espaço coletivo. Esta abertura ao encontro do outro corrobora o entendimento de Levinas (1993, p. 49) quando revela que "a relação com o Outro questiona-me, esvazia-me de mim mesmo e não cessa de esvaziar-me, descobrindo-me possibilidades sempre novas".

$\mathrm{O}$ deslocamento de encontrar o Outro com uma postura hospitaleira permitiu à professora a reflexão de suas ações para e com as crianças. O gesto de documentar, construir narrativas, permite à professora um deslocamento de olhar, possibilitando a construção de outra imagem de criança, participativa, criativa, autora e produtora de cultura.

Ao longo da experiência formativa com as professoras, por meio do compartilhamento de suas falas, escritos, imagens fotográficas e audiovisuais, foi possível perceber que, ao compartilhar, elas refletiam o seu fazer ao mesmo tempo em que podiam se identificar com os registros das colegas, e davam outros significados para o que viam e faziam. $\mathrm{O}$ ato de documentar o vivido com as crianças acolheu o inesperado, o imprevisível, valorizando o dia a dia no encontro com o outro. "Tratou de valorar a riqueza de significados de práticas cotidianas" (SIMIANO, 2015, p. 114).

No compartilhamento das narrativas cotidianas ficou evidente o quanto as professoras desejam compartilhar aquilo que as toca, intriga, inquieta. Oportunizar meios e espaços para 
ouvir e serem ouvidas vai ao encontro da ética, no sentido de acolher o Outro. E, nesse encontro com o outro, "eu me reencontro diante do Outro" (LEVINAS, 1993, p. 50). A partir dessa premissa, a professora Márcia conta sobre seu encontro com Isabella.

Porque eu saí daqui no outro encontro... assim... eu tive dúvida, até conversei com a Sônia. O que me marca, o que marcou muito foi uma experiência com uma única aluna. Aí pensei: 'Será que eu posso documentar de uma única criança?’ Então... eu estou observando, ainda mais, na verdade, esta minha aluna: Isabella. Ela tem diagnóstico de autismo. E aquele autismo clássico, bem clássico: ela não fala, ela não tem... ela não socializa com as crianças em momento algum (áudio transcrito, relato professora Márcia - 20/09/2018).

Olhar o novo, o diferente, o outro. Acolher o enigmático. "Isso" convoca. A presença do Outro que está diante de mim provoca e convoca a uma resposta. O encontro com o Outro não é neutro, exige um posicionamento. "O questionamento de si é precisamente o acolhimento do absolutamente outro. A epifania do absolutamente outro é rosto em que o Outro me interpela e me significa uma ordem por sua nudez, por sua indigência. Sua presença é uma intimação para responder” (LEVINAS, 1993, p. 53). Ao manifestar essa inquietação diante da presença do Outro, há um deslocamento, um movimento, uma abertura à alteridade que, por meio da sua presença, questiona e exige uma resposta à sua singularidade. Como educar e cuidar de uma criança com necessidades tão específicas? Uma criança com diagnóstico autista poderia aprender? Desenhar? Brincar? Parece haver nada diante de tantos nãos...

Frente às dificuldades de se estar em companhia, a importância de construir um lugar de partilha deve ser ressaltada. Nesse sentido, a Educação Infantil como uma instituição responsável pela educação e cuidado das crianças em complementaridade à família, ocupa lugar e função fundamentais. Assim, mesmo com as tensões e mal-estar diante de Isabella, concordamos com Simiano e Vasques (2015, p. 286) e "apostamos na fecundidade do encontro com a alteridade no âmbito educativo a fim de germinarem novas formas de se estar com o outro". Como responder a essa criança que não fala, mas que, com sua presença, me convoca?

No percurso da experiência formativa, tecida pela via do processo da documentação pedagógica, a professora foi convocada a ler, reconhecer, valorizar, mediar, narrar e documentar, ofertando possibilidades educativas que potencializassem o desenvolvimento psíquico, cognitivo e social de Isabella. Nesse processo, a professora foi mobilizada a supor em Isabella um sujeito. Mariotto (2009) pontua que a suposição do bebê e da criança pequena como um sujeito por parte do adulto é de suma importância no seu processo de constituição subjetiva. No caso de crianças que se defrontam com dificuldades ou vicissitudes nesse processo, tal movimento torna-se ainda mais crucial para colocar em marcha ou retomar as bases dessa constituição. Emprestar a palavra para uma criança que ainda não fala pode auxiliá-la a ser inscrita na linguagem e, posteriormente, falar em nome próprio. 
Desde os primeiros encontros, a professora foi convidada a documentar Isabella na interação com o meio e o outro. Nas palavras da professora:

Foi algo que me marcou muito. Por exemplo, o lanche, a hora do lanche. Ela não aceitava fazer com a turma. Aí a gente confeccionou com a turma um jogo americano. Aí eu colocava no lugar dela e ela jogava longe, porque ela não queria aquele jogo americano lá. Na hora do lanche, tinha que dar o lanche na boca, não comia sozinha. Foi indo, foi indo... eu não desisti... aí agora eu coloco o jogo americano dela na mesa, ela olha e já sabe que aquele lá é o dela. Ela já vai lá, senta naquele lugar que tem o jogo americano dela, já está buscando a lancheira na mochila, já tá abrindo, botando o lanche ali. Já está comendo com talher, então assim, isso pra mim, me tocou muito! [sic] (Áudio transcrito, relato da professora Márcia - 20/09/2018).

É o Outro que me convoca a sair do meu lugar de origem e fazer este deslocamento, exigindo uma resposta, chama à responsabilidade de encontrar um sentido para esta relação entre o Eu, o Outro e o Mundo. Ir ao encontro do novo, do estranho, do diferente, exige uma abertura à alteridade, procurar conhecer o desconhecido e encontrar um meio de chegar até ele. "Abandonar os caminhos mais rápidos, assumir que nosso conhecimento é limitado e colocar-nos no lugar de quem não sabe tudo do outro, porque nossa criança não é óbvia, não é uma obra clara, é sempre um grande desafio" (SIMIANO; VASQUES, 2015, p. 287).

Estar frente a frente com a diversidade, que interroga, que traz desconforto, é um grande desafio: é preciso se colocar nesse lugar, de quem não sabe, que desconhece, mas que está disposto a encontrar... Para a professora, receber uma criança autista não é fácil. Causa desconforto, desacomoda, inquieta, leva ao encontro da fragilidade humana. É difícil sair ileso e não ser afetado pela diferença. Não é um processo fácil incluir o diferente, mas é preciso.

Com a professora Márcia não foi diferente. O processo de construção de sua narrativa não foi fácil. Em um primeiro momento, a professora trouxe muitos registros fotográficos como forma de contar a experiência. Seria possível ofertar uma narrativa só a partir de imagens? Larrosa (2016) afirma que o excesso de informação mata a experiência. Algumas vezes, na ânsia de contar o vivido, queremos dar conta de tudo e acabamos nos perdendo pelo excesso. Nesses momentos é necessário parar, olhar, escutar e refletir o vivido, encontrar formas de interpretar e narrar a experiência. Foi no encontro com o outro, na interpretação em companhia que a professora foi pouco a pouco encontrando uma forma de narrar, de ofertar uma narrativa capaz de traduzir em palavras o vivido. "A vida cotidiana precisa ser traduzida em palavras" (SIMIANO, 2015, p. 108).

No sentido de criar possibilidades educativas que permitam acolher, respeitar e valorizar as diferenças de cada criança, a pedagogia italiana propõe uma forma de documentar por meio de diários. "Diário não é uma forma de arquivo, é uma borda de sentido, hábil a potencializar, assim, a experiência” (SIMIANO, 2015, p. 123). Na construção de diários não são documentados apenas grandes acontecimentos, datas comemorativas, ao contrário, as páginas ilustram a força dos pequenos acontecimentos do dia a dia. E foi assim que a 
professora Márcia buscou dar visibilidade ao processo de interação com o meio e o outro, e surgiu a documentação em forma de diário intitulado As Conquistas de Isabella, como mostra a figura 2 a seguir.

Figura 2 - Páginas da documentação pedagógica: As Conquistas de Isabella

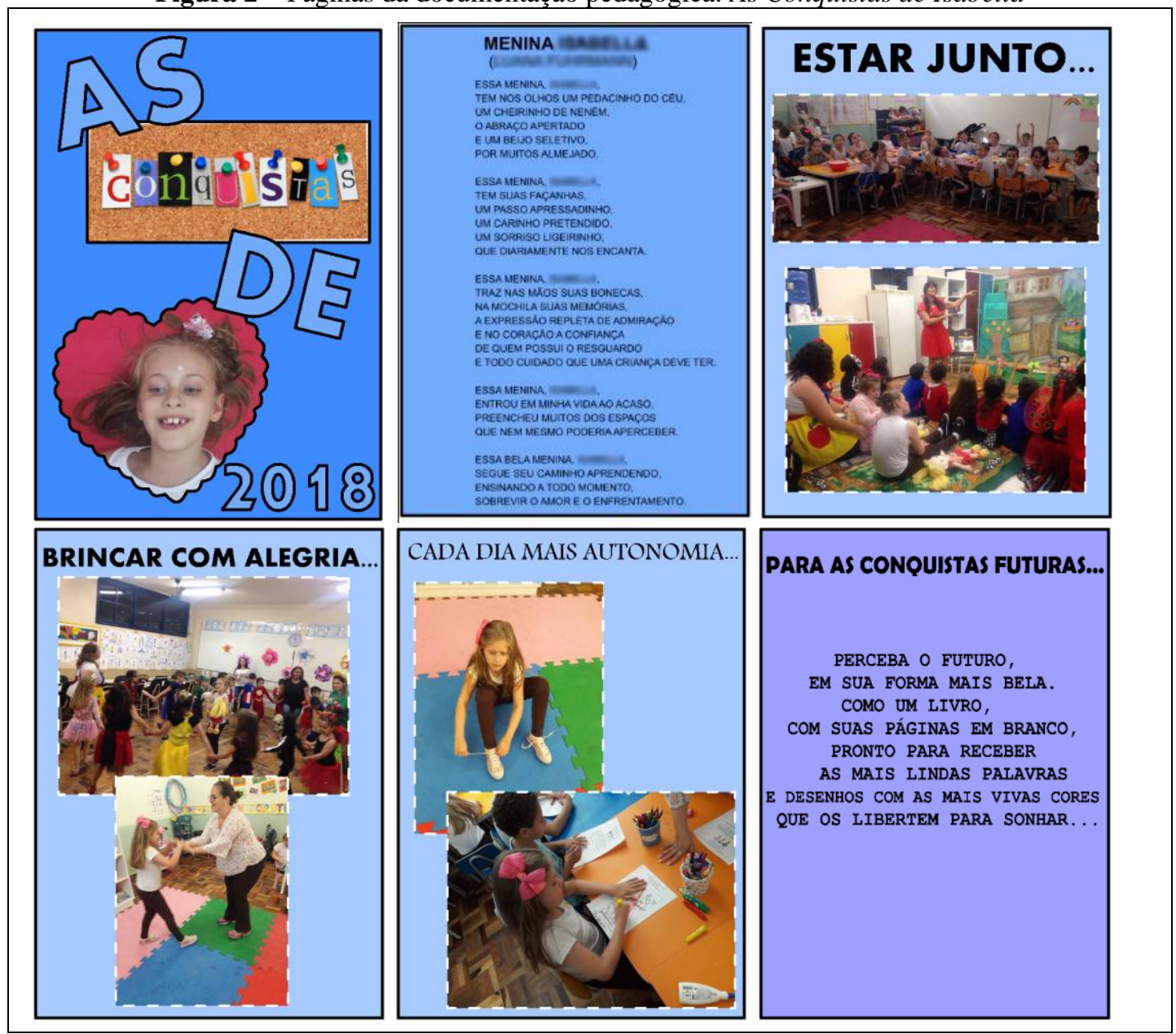

Fonte: Acervo da pesquisadora (2018).

Respeitar o outro na sua forma de ser e estar no mundo é acolher esse outro, que é diferente, mas tem o direito de sentir-se pertencente ao contexto coletivo. Por meio da narrativa, no percurso formativo, a professora compartilhou essa experiência que a tocou, que lhe aconteceu, lançando um olhar acolhedor e que reconhece a singularidade. Simiano e Vasques (2015, p. 294) lembram que "frente à fragilidade da condição humana e às desmesuras do humano, é preciso apostar na palavra como forma de construir outros sentidos e possibilidades de pertencimento".

A documentação As Conquistas de Isabella configurou-se como um modo peculiar de desvelar sentidos, narrar e constituir experiências. Por meio da narrativa, a professora ofertou 
um sentido para essa criança, contribuindo com o seu processo de constituição subjetiva, reconhecendo suas conquistas, valorizando o seu modo de ser e estar no mundo. No gesto de documentar, a professora Márcia cria visibilidades não apenas para aquilo que é aparente e passa a construir uma forma de pensar e um modo de acolher esse outro que a interpela. "O Outro que provoca este movimento ético de consciência, que desordena a boa consciência do Mesmo, consigo próprio, comporta um excesso inadequado à intencionalidade" (LEVINAS, 1993, p. 53). Entrar em relação com o inapreensível remete à ideia do desejo. "É isto o desejo: queimar de um fogo diverso que o da necessidade que a saturação apaga, pensar além do que se pensa" (LEVINAS, 1993, p. 53). O encontro com o Outro, muitas vezes, provoca-nos a pensar além do que já sabemos, faz com que tenhamos que sair da zona do conforto e buscar outros meios de aproximação. Esta é a responsabilidade para com o Outro, encontrar meios para que todos possam se sentir pertencidos.

Acolher as diferenças é educar para a humanização. De acordo com Mariotto (2009, p. 45), a partir de uma perspectiva psicanalítica, "humanizar, portanto, é marcar o sujeito com o significante, operação que abre espaço para a desbiologização do corpo e sua amarração [...] à palavra". Praticar o acolhimento é criar laços, elos capazes de gerar sentido de pertencimento no reconhecimento da diversidade. Kramer (1999) ressalta que o objetivo principal da educação é formar uma sociedade que reconheça o outro nas suas diferenças, $o$ que implica a construção de uma ética, "pois o que nos singulariza como seres humanos é justamente nossa pluralidade. Somos constituídos na diferença" (KRAMER, 1999, p. 276).

A aposta na proposta de uma experiência formativa tecida pelo processo de documentar concentra no cerne a aposta na função constitutiva da educação, na força da palavra, no processo de documentar como um dispositivo de reinvenção das possibilidades de ser e estar em contextos educativos.

\section{Considerações finais}

Desde a mais tenra idade, a alteridade é capaz de criar novas formas de ser e habitar o mundo. No presente texto, relatamos uma experiência formativa, a partir de um curso de extensão, que foi tecida pelo percurso de documentar na Educação Infantil, apresentamos fragmentos, breves passagens, que apostamos serem significativas para compor outras narrativas sobre ser professor, ser criança, estar em instituição educativa.

Sabemos o quanto a organização de práticas pedagógicas cotidianas é um dos principais nós da pedagogia. Oportunizar tempo e espaço para que os professores possam falar de suas experiências no cotidiano educativo ainda é um desafio. Quais os espaços e tempos destinados para a formação continuada de professores de Educação Infantil? Como ocupar tal função de ler e narrar as experiências do cotidiano? É possível compor narrativas atentas às singularidades, à coletividade, à experiência?

A Educação Infantil, a partir do diálogo com as diretrizes, implica a construção de experiências educativas capazes de reconhecer, acolher e valorizar a reinvenção dos processos de educar. Trata-se, assim, de um movimento que evoca a necessidade de construir 
dispositivos que permitam maior compreensão acerca da complexidade dos processos sociais, subjetivos e educacionais implicados no cotidiano das instituições de Educação Infantil. Ao longo da experiência formativa, pela via da documentação pedagógica, o professor é convidado a narrar e inscrever sua própria experiência. Ao tomar posição de autor, percebem-se deslocamentos importantes nas formas de ler e significar as (im)possibilidades de acolhimento e reconhecimento do Outro na Educação Infantil.

\section{Notas}

1. Para garantir o sigilo das informações e em atendimento aos cuidados éticos que uma pesquisa científica deve ter, optamos por adotar nomes fictícios para as participantes.

\section{Referências}

ANDRÉ, M. O que é um Estudo de Caso Qualitativo em Educação? Revista da FEEBA, Educação e Contemporaneidade, Salvador, BA, v. 22, n 40, p. 95-103, jul./dez. 2003.

ARENDT, H. A condição humana. São Paulo: Editora Forense-Universitária, 2007.

BÁRCENA, F.; MÈLICH, J-C. La Educacion como aconteciemiento ético: Paidós, 2000.

BENJAMIN, W. O narrador: considerações sobre a obra de Nikolai Leskov. In: Magia e técnica, arte e política: ensaios sobre literatura e história da cultura. São Paulo: Brasiliense, 1994. p. 197-221.

BRASIL. Ministério da Educação. Resolução n. 5/2009, de 17 de dezembro de 2009. Diretrizes curriculares nacionais para a educação infantil. Brasília: Conselho Nacional de Educação, Câmara de Educação Básica - CEB, dez. 2009.

BRASIL. [Constituição (1988)]. Constituição da República Federativa do Brasil: promulgada em 5 de outubro de 1988. 55. ed. atual. São Paulo: Saraiva, 2018.

BRASIL. Ministério da Educação. Secretaria de Educação Básica. Diretrizes curriculares nacionais para a educação infantil. Brasília, DF: MEC/SEB, 2010.

COUTINHO, A. S. As crianças no interior da creche: a educação e o cuidado nos momentos de sono, higiene e alimentação. 2002. Dissertação (Mestrado em Educação) - Universidade Federal de Santa Catarina, Florianópolis, 2002.

FREUD, S. O inquietante (1919). In: FREUD, S. História de uma neurose infantil: (“o homem dos lobos”): além do princípio do prazer e outros textos (1917-1920). São Paulo: Companhia das Letras, 2010. p. 328376.

GANDINI, L.; GOLDHABER, J. Duas reflexões sobre a documentação. In: GANDINI, L.; EDWARDS, C, P. Bambini: A abordagem italiana à educação infantil. Porto Alegre: Artmed, 2002. cap. 10. p. 151-169.

GUIMARÃES, O. S. M. O processo de documentação pedagógica em uma experiência formativa com professores da educação infantil: um encontro com o princípio ético. 2019. Dissertação (Mestrado em Educação) - Universidade do Sul de Santa Catariana, Tubarão, 2019.

HERMANN, N. Ética \& Educação: outra sensibilidade. 1. ed. Belo Horizonte: Autêntica Editora, 2014. (Coleção Temas \& Educação).

JOHANN, J. R. Educação e ética: em busca de uma aproximação [recurso eletrônico]. Porto Alegre: Edipucrs, 2009. Disponível em: http://www.pucrs.br/orgaos/edipucrs/. Acesso em: 10 ago. 2019. 
KRAMER, S. Infância e Educação: O necessário caminho de trabalhar contra a barbárie. Infância e Educação Infantil. Campinas, SP: Papirus, 1999. (Coleção prática pedagógicas vários autores). cap. 11. p. 269-279.

LARROSA, J. Notas sobre a experiência e o saber da experiência. Revista Brasileira de Educação, Campinas, n. 19, jan./fev./mar./abr. 2002.

LARROSA, J. Tremores: escritos sobre experiência. Tradução de Cristina Antunes, João Wanderley Geraldi. 1. ed.; $2^{\mathrm{a}}$ Reimp. Belo Horizonte: Autêntica Editora, 2016. (Coleção Educação: Experiência e Sentido).

LEVINAS, E. Totalidade e infinito. Lisboa, Portugal: Edições 70 Ltda. 1980.

LEVINAS, E. Humanismo do outro homem. Petrópolis, RJ: Vozes, 1993.

MALAGUZZI, L. Histórias ideias e filosofia básica. In: EDWARDS, C; GANDINI, L.; FORMAN, G. As cem linguagens da criança. Porto Alegre: Artes Médicas, 1999. p. 48-62.

MARIOTTO, R. M. M. Cuidar, educar e prevenir: as funções da creche na subjetivação de bebês. São Paulo: Escuta, 2009.

RINALDI, C. Diálogos com Reggio Emília: escutar, investigar e aprender. Tradução de Vania Cury. 4. ed. Rio de Janeiro: Paz e Terra, 2017.

ROSSETI-FERREIRA, M. C. A pesquisa na universidade e a educação da criança pequena. Cadernos de Pesquisa, v. 67, p. 59-63, nov. 1988.

SCHMITT, R. V. "Mas eu não falo a língua deles!”: as relações sociais de bebês num contexto de educação infantil. 2009. Dissertação (Mestrado em Educação) - Universidade Federal de Santa Catarina, Florianópolis, 2009.

SIMIANO, L. P. Colecionando Pequenos Encantamentos...: A documentação Pedagógica como uma narrativa peculiar para e com as crianças bem pequenas. 2015. Tese (Doutorado em Educação) Universidade Federal do Rio Grande do Sul, Porto Alegre, 2015.

SIMIANO, L. A documentação pedagógica como narrativa peculiar na creche. Pro-Posições [online], v. 29, n. 3, p. 164-186, 2018. ISSN 1980-6248. http://dx.doi.org/10.1590/1980-6248-2017-0002. Disponível em: http://www.scielo.br/scielo.php?script=sci_arttext\&pid=S0103-73072018000300164\&lng=pt\&tlng=pt. Acesso em: 30 jun. 2019.

SIMIANO, L. P.; VASQUES, C. K. Entre palavras e vida, uma leitura sobre documentação pedagógica e narrativa no contexto da educação infantil inclusiva. Revista Reflexão e Ação, Santa Cruz do Sul, v. 23, n. 3, p. 281-298, set./dez. 2015.

\section{Correspondência}

Onileda de Souza Matta Guimarães. Pedagoga e mestra em Educação pela UNISUL. Professora do Estado de Santa Catarina e da Rede Municipal de Imbituba (SC).

ORCID: 0000-0002-5666-6579.

E-mail: od.matta@bol.com.br

Luciane Pandini Simiano. Pedagoga e Doutora em Educação. Professora do Programa de Pós-graduação em Educação da Universidade do Sul de Santa Catarina - UNISUL.

ORCID: 0000-0001-8378-2359.

E-mail: lucianepandini@gmail.com 
Simone Bicca Charczuk. Psicóloga e Doutora em Educação. Professora da Faculdade de Educação Universidade Federal do Rio Grande do Sul - UFRGS.

ORCID: 0000-0003-1947-1366.

E-mail: sibicca@gmail.com

Texto publicado em Currículo sem Fronteiras com autorização das autoras. 